\title{
(2) OPEN ACCESS \\ The hidden cost of colonoscopy including cost of reprocessing and infection rate: the implications for disposable colonoscopes
}

\author{
Sara Larsen (10 , Anthony Kalloo, ${ }^{2}$ Susan Hutfless (1) 2,3,4
}

\begin{abstract}
- Additional material is published online only. To view please visit the journal online (http://dx.doi.org/10.1136/ gutjnl-2019-319108)
\end{abstract}

${ }^{1}$ School of Medicine and Health, Aalborg University, Aalborg, Denmark

${ }^{2}$ Department of Medicine, Division of Gastroenterology and Hepatology, Johns Hopkins University, Baltimore, Maryland, United States

${ }^{3}$ Gastrointestinal Epidemiology Research Center, Johns Hopkins University, Baltimore, Maryland, United States

${ }^{4}$ Department of Epidemiology, Johns Hopkins University Bloomberg School of Public Health, Baltimore, Maryland, United States

\section{Correspondence to}

Dr Susan Hutfless, Division of Gastroenterology, Johns Hopkins University, Baltimore, MD 21287, USA;

shutfle1@jhmi.edu

Received 16 May 2019

Revised 23 July 2019

Accepted 8 August 2019

Published Online First

14 August 2019

Check for updates

(C) Author(s) (or their employer(s)) 2020. Re-use permitted under CC BY-NC. No commercial re-use. See rights and permissions. Published by BMJ.

To cite: Larsen S, Kalloo A Hutfless S. Gut

2020:69:197-200.

\section{MESSAGE}

Multiple studies have documented a high rate of contaminated colonoscopes after reprocessing. Contaminated reusable colonoscopes may increase the risk of device-related patient infections. As disposable colonoscopes enter the market, they may play a role in infection prevention and may be cost-effective at some facilities or in high-risk patients. Using a micro-costing approach, this study found that the cost per colonoscopy including purchase, maintenance and reprocessing ranges from US $\$ 188.64$ at high volume centres (3000 annual procedures) to US\$501.16 at low volume centres (1000 annual procedures). Accordingly, per-procedure capital costs range from US\$87.48 to US\$262.45; repair costs range from US\$68.77 to US $\$ 206.32$; cleaning supplies and labour costs US\$32.39 and infections requiring hospitalisation cost US $\$ 20.12$ to US\$46.52. As disposable colonoscopes enter the market, low volume centres are most likely to achieve cost savings. Determining if postprocedural infection rates differ with reusable vs disposable colonoscopes is needed.

\section{In more detail}

Each year more than 15 million colonoscopy procedures are performed in the USA and the number is increasing. ${ }^{1}$ Colonoscopy is generally thought to be safe; however, patients are sometimes hospitalised afterwards, due to infections that may have been transmitted via contaminated colonoscopes (MAUDE Adverse Event Report). ${ }^{2}$ Colonoscopy-related infections and complications have been reported in multiple studies, although at lower rates compared with endoscopic retrograde cholangiopancreatography (ERCP). ${ }^{145}$ Guideline revisions in response to endoscope-associated infections require healthcare institutions to invest more resources in the high-level disinfection process or conversion to sterilisation (Ofstead et al). ${ }^{5} 6$ Despite colonoscopy being the highest volume GI procedure, the true cost and time associated with reusable colonoscopes are unknown. The purpose of this study was to explore realworld costs associated with reusable colonoscopes including capital costs and costs associated with reprocessing, personnel, maintenance, repair and postprocedural hospitalisation due to infection.

All cost data related to the usage of reusable colonoscopes were obtained at a high-volume outpatient endoscopy referral centre (Johns
Hopkins Hospital, Baltimore, Maryland, USA) by tracking 25 colonoscope reprocessing procedures over a 3-day period. Cost data were collected in US dollars (\$) using a micro-costing approach as this method allows for precise assessment of economic costs. ${ }^{7}$ Cost per use of reusable colonoscopes were calculated fora range of annual procedures $(1000,2000$ and 3000) performed with a fleet of 20 colonoscopes (US\$35 000 per colonoscope) (Addendum) and extrapolated to different numbers of colonoscopes and procedure volumes (table 1). Automated endoscopic reprocessor (AER) cost calculations assumed two AERs to reprocess the colonoscopes available at the endoscopy unit (US\$47 646.80 per AER (US\$13863.01/year)) regardless of volume. Capital costs of the colonoscopes and their associated hardware and software were amortised over a 5-year period, and a discount rate of 3.5\% was used to calculate the present value of capital expenditures. The AER and drying cabinets were amortised over an 8-year period. Average time spend on manual reprocessing was calculated for each reprocessing step. Costs related to initial and recurring training, education of personnel, time spent handling documentation for repair and retraining for compliance with latest reprocessing guidelines were not included. Average cost of repairs per AER is US\$7831.25 per year. Each colonoscope was repaired 3.04 times per year on average at US\$8609.94 per year (based on Johns Hopkins Service Contract Performance Reports, 2018).

Infection rates were 3.7 and 1.6 per 1000 procedures. ${ }^{14}$ Costs of infection-related hospitalisation were collected from HCUPnet ${ }^{8}$ which samples the 2016 National Inpatient Sample and the International Classification of Diseases 10th revision codes A04 and A09. Cost of infection was based on the assumption that all infected patients are treated at a hospital. Cost per treatment is US\$12 574.28. Costs of postendoscopic infection hospitalisation per procedure were calculated by multiplying the infection rate and cost per hospitalisation (eg (1.16/1000) $\times$ US\$12 574.28).

The cost associated with reusable colonoscopes ranges from US $\$ 188.64$ to US $\$ 501.16$ per procedure based on 20 colonoscopes (table 1 and online supplementary table 1 (addendum)). The perprocedure cost is highly dependent on the number of annual procedures and colonoscopes available at the facility (table 2). The time associated with 
Table 1 Estimation of the per-procedure costs of reusable colonoscopes by varying number of annual procedures and number of colonoscopes

\begin{tabular}{|c|c|c|c|c|}
\hline Summary of costs & 1000 procedures (US\$) & $\begin{array}{l}2000 \text { procedures } \\
\text { (US\$) }\end{array}$ & $\begin{array}{l}3000 \text { procedures } \\
\text { (US\$) }\end{array}$ & $\begin{array}{l}\text { Costs that will remain with disposable } \\
\text { endoscope }\end{array}$ \\
\hline Capital costs & & & & $\begin{array}{l}\text { Yes. Purchase of disposable colonoscope } \\
\text { per procedure only and monitor (lifespan } \\
\text { approximately } 5 \text { years) }\end{array}$ \\
\hline 10 colonoscopes & 184.93 & 92.47 & 61.64 & \\
\hline 20 colonoscopes & 262.45 & 131.22 & 87.48 & \\
\hline 35 colonoscopes & 378.73 & 189.36 & 126.24 & \\
\hline 50 colonoscopes & 495.00 & 247.50 & 165.00 & \\
\hline Repair costs & & & & No \\
\hline 10 colonoscopes & 120.22 & 60.11 & 40.07 & \\
\hline 20 colonoscopes & 206.32 & 103.16 & 68.77 & \\
\hline 35 colonoscopes & 335.47 & 167.74 & 111.82 & \\
\hline 50 colonoscopes & 464.62 & 232.31 & 154.87 & \\
\hline $\begin{array}{l}\text { Precleaning, leak testing, manual cleaning, visual } \\
\text { inspection, high-level disinfection, storage (including } \\
\text { personal protective equipment) }\end{array}$ & 25.23 & & & No \\
\hline $\begin{array}{l}\text { Personnel time during pre-cleaning through high-level } \\
\text { disinfection }\end{array}$ & 7.16 & & & No \\
\hline $\begin{array}{l}\text { Infection-related treatment } \\
\text { Per-procedure cost at different infection rates: } 1.6 / 1000^{1} \text { and } \\
0.37 / 100^{4}\end{array}$ & $20.12-46.52$ & & & $\begin{array}{l}\text { Not for infections caused by endoscopic cross- } \\
\text { contamination }\end{array}$ \\
\hline \multicolumn{5}{|l|}{ Total } \\
\hline 10 colonoscopes & $357.66-384.07$ & $205.08-231.49$ & $154.23-180.63$ & \\
\hline 20 colonoscopes & $521.28-547.69$ & $286.89-313.30$ & $208.76-235.17$ & \\
\hline 35 colonoscopes & $766.71-793.11$ & $409.61-436.01$ & $290.57-316.98$ & \\
\hline 50 colonoscopes & $1012.12-1038.54$ & $532.32-558.73$ & $372.38-398.79$ & \\
\hline
\end{tabular}

Costs marked with bold font are the base-case numbers (ie, based on 20 colonoscopes). The message of this study is based on the base-case results. Other estimates are used to increase transparency and to make data comparable to other facilities.

*Assumption: all infected patients are treated at a hospital.

manual reprocessing was approximately 19 min per procedure. Divided into three major cost categories, the capital costs per procedure range from US\$81.21 to US $\$ 243.63$, costs of repair ranged from US\$68.77 to US\$206.59, and the costs of cleaning including labour ranged from US\$39.91 to US\$50.11. In addition, the costs of hospitalisation due to infection following colonoscopy ranged between US $\$ 20.12$ and US\$46.52 per procedure.

\section{COMMENTS}

It costs between US\$188.64 and US\$501.16 per colonoscopy including purchase, maintenance and reprocessing. Per-procedure costs increase an additional US\$20.12 to US\$46.52 if the postprocedural infections are included. Previous colonoscopy cost estimates range from US\$114.07 to US\$280.71 to reprocess the colonoscope; they did not consider the capital costs to purchase the equipment nor pay for postprocedural infections (Ofstead et $a l)^{6}$ When we included only reprocessing and repair, our results are similar to the previous estimate at US\$101.16 to US\$238.71. The cost per colonoscopy is volume dependent based on the capital requirements of the colonoscope, its hardware and software and the AER, which was also found for duodenoscope and bronchoscope costs (Bang et al, ${ }^{9}$ Ofstead et al ${ }^{10}$ ).

Our cost estimates are minimum estimates. The true cost may be even higher once overhead costs, additional reprocessing and equipment costs are considered (eg, additional reprocessing after 7 days storage, cost of disposing single-use accessories, conducting internal audits, water and electricity, etc). At facilities with many colonoscopes available, the cost of additional reprocessing after 7 days storage might be substantial due to a low volume per colonoscope. Previous reprocessing estimates range from US\$20 to US\$150 (average: US\$69) ${ }^{11}$ which is similar to our cost estimate of US\$32.39. This study was not able to account for the cost of disposable colonoscopes because they have not entered the market yet. Disposal costs for colonoscopes will be a new cost, although it is anticipated to be similar to the cost of disposable bronchoscope disposal (US\$0.06 per procedure). ${ }^{12}$ Additionally, the environmental impact is somewhat equal for disposable bronchoscopes and reusable bronchoscopes but is highly dependent on the different reprocessing standards. ${ }^{13}$ The per-procedure cost is dependent on differences in repair rate and costs, staffing costs and capital costs which may modify these estimates. Time spent on reprocessing in this study was relatively low (19 min compared with $76 \mathrm{~min}$ ) (Ofstead et $\mathrm{al}^{14}$ ) and may reflect the focus on colonoscopes exclusively in this study.

The cost of reusable colonoscopes is highly dependent on the settings at each facility and especially the number of colonoscopes and annual volume of procedures. Disposable colonoscopes may decrease device-related infection transmission and may prove cost-effective for some facilities, particularly those with low-volume and high-infection risk patients. The true impact of disposable colonoscopes on infection and complication rates, cost-effectiveness and functionality for more difficult therapeutic procedures will remain unknown until they are widely available.

Acknowledgements We want to thank the Johns Hopkins Endoscopy Department for their cooperation and help performing this study. Author contributions: Data collection, data analysis, and manuscript writing was performed by Sara Larsen. Revision of manuscript for important intellectual content was performed by all authors

Contributors Data collection, data analysis and manuscript writing was performed by SL. Revision of manuscript for important intellectual content was performed by all authors. 


要

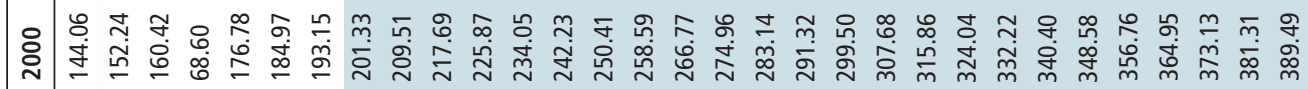

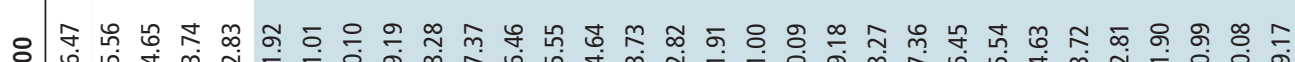

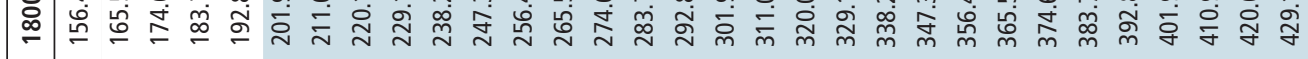

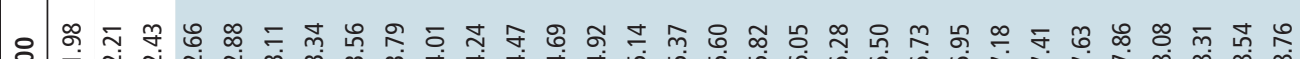

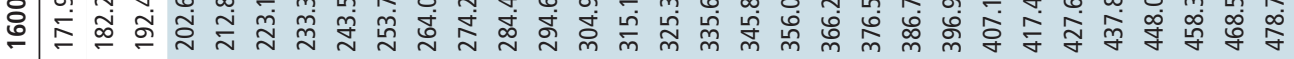

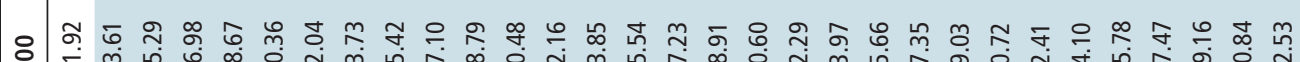

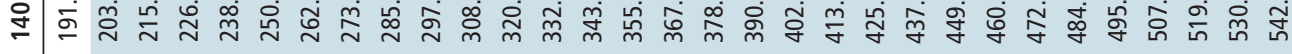

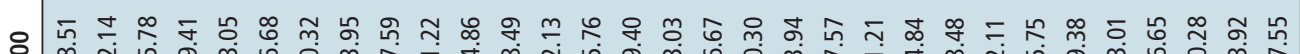

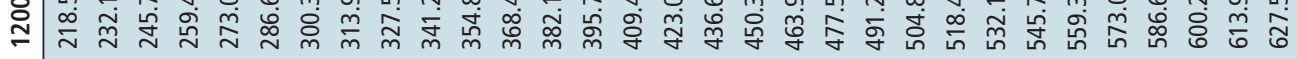

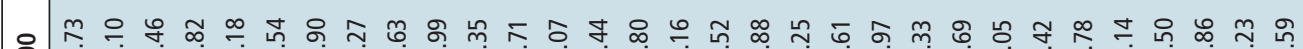

$\stackrel{8}{\circ}$ 刿 交

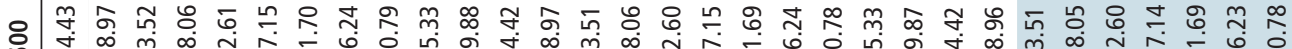

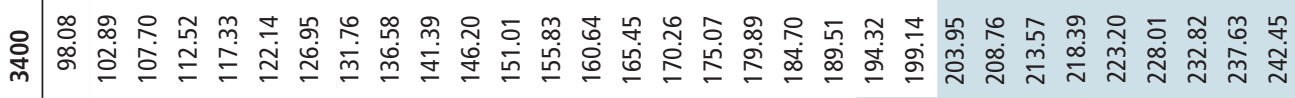

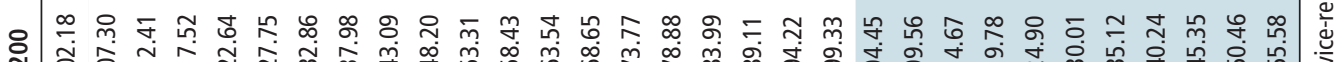

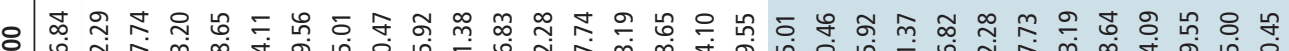
느 \& 우 8 궁 œ

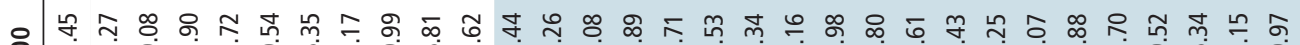
৪ бํำ ฟ

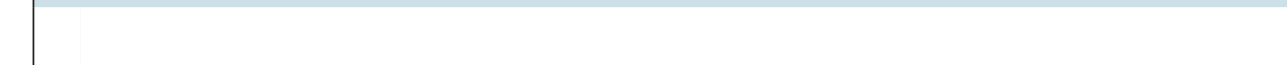

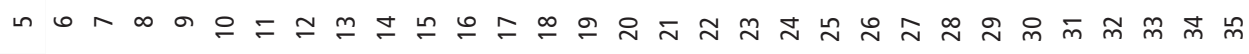

(1)

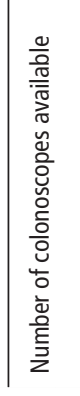


Funding The authors have not declared a specific grant for this research from any funding agency in the public, commercial or not-for-profit sectors.

Competing interests SL received travel support from Ambu A/S, Ballerup, Denmark as part of her master's thesis. SH has received speaker fees and research support from Cantel. ANK is a founding member and equity holder/Apollo Endosurgery.

Patient consent for publication Not required.

Provenance and peer review Not commissioned; internally peer reviewed.

Open access This is an open access article distributed in accordance with the Creative Commons Attribution Non Commercial (CC BY-NC 4.0) license, which permits others to distribute, remix, adapt, build upon this work non-commercially, and license their derivative works on different terms, provided the original work is properly cited, appropriate credit is given, any changes made indicated, and the use is non-commercial. See: http://creativecommons.org/licenses/by-nc/4.0/.

\section{ORCID iDs}

Sara Larsen http://orcid.org/0000-0002-3887-4948

Susan Hutfless http://orcid.org/0000-0002-6311-2611

\section{REFERENCES}

1. Wang P, Xu T, Ngamruengphong $\mathrm{S}$, et al. Rates of infection after colonoscopy and osophagogastroduodenoscopy in ambulatory surgery centres in the USA. Gut 2018;67:1626-36.

2. U.S. Food and Drug Administration. MAUDE adverse event report: OLYMPUS medical systems CORP. EVIS EXERA LLL COLONOVIDEOSCOPE. Available: https://www. accessdata.fda.gov/scripts/cdrh/cfdocs/cfMAUDE/detail.cfm?mdrfoi_id=8143738\& pc=FDF [Accessed 24 Apr 2019]
3. U.S. Food and Drug Administration. Adverse event without identified device or use problem. Available: https://www.accessdata.fda.gov/scripts/cdrh/cfdocs/cfmaude/ detail.cfm?mdrfoi_id=8143728\&pc=FDF [Accessed 24 Apr 2019]

4. Lin J-N, Wang C-B, Yang C-H, et al. Risk of infection following colonoscopy and sigmoidoscopy in symptomatic patients. Endoscopy 2017;49:754-64.

5. Rutala WA, Kanamori H, Sickbert-Bennett EE, et al. What's new in reprocessing endoscopes: Are we going to ensure "the needs of the patient come first" by shifting from disinfection to sterilization? Am J Infect Control 2019;47:A62-A66.

6. . Available: https://bsci63-tage.adobecqms.net/content/dam/bostonscientific/uro-wh/ portfolio-group/LithoVue/pdfs/Sterilization-Resource-Handout.pdf

7. Xu X, Grossetta Nardini HK, Ruger JP. Micro-costing studies in the health and medical literature: protocol for a systematic review. Syst Rev 2014;3:47.

8. . Available: https://hcupnet.ahrq.gov/\#setup

9 Bang JY, Sutton B, Hawes R, et al. Concept of disposable duodenoscope: at what cost? Gut 2019:68:1915-7.

10. International Association of Healthcare Central Service Materiel Management. Managing bronchoscope quality and cost: results of a real-world study. Available: https://www.ambu.com/Files/Files/Ambu/Investor/News/English/2019/Managing\% 20Bronchoscope $\% 20$ cost $\% 20 a \% 20$ real\%20world\%20study.pdf

11. Almario CV, May FP, Shaheen NJ, et al. Cost utility of competing strategies to prevent endoscopic transmission of carbapenem-resistant Enterobacteriaceae. Am J Gastroenterol 2015:110:1666-74.

12. Perbet $S$, Blanquet $M$, Mourgues $C$, et al. Cost analysis of single-use (Ambu ${ }^{\circledR}$ aScope $^{\mathrm{TM}}$ ) and reusable bronchoscopes in the ICU. Ann Intensive Care 2017:7:3.

13 Sørensen BL, Grüttner H. Comparative study on environmental impacts of reusable and single-use bronchoscopes. Am J Environ Protec 2018;7.

14. International Association of Healthcare Central Service Materiel Management. A glimpse at the true cost of reprocessing endoscopes: results of a pilot project. Available: https://www.bostonscientific.com/content/dam/bostonscientific/uro-wh/ portfolio-group/LithoVue/pdfs/Sterilization-Resource-Handout.pdf 